\title{
Partial sequence analysis of the actin gene and its potential for studying the phylogeny of Candida species and their teleomorphs
}

\author{
1 Molecular Mycology \\ Laboratory, The University \\ of Sydney/Westmead \\ Hospital, ICPMR, Level 3, \\ Rm 3114A, Darcy Road, \\ Westmead, NSW 2145, \\ Australia \\ 2 Technische Universität \\ Berlin, Institut für \\ Mikrobiologie und \\ Genetik, Gustav-Meyer- \\ Allee 25, D-13355 Berlin, \\ Germany
}

\author{
Heide-M. Daniel, ${ }^{1,2}$ Tania C. Sorrell ${ }^{1}$ and Wieland Meyer $^{1}$ \\ Author for correspondence: Heide-M. Daniel. Tel: +6129845 6332. Fax: +61 298915317. \\ e-mail: heidem@westgate.wh.usyd.edu.au
}

\begin{abstract}
The actin gene has been studied as a potential phylogenetic marker for selected members of the anamorphic genus Candida and seven related teleomorphic genera (Debaryomyces, Issatchenkia, Kluyveromyces, Saccharomyces and Pichia from the Saccharomycetaceae; Clavispora and Metschnikowia from the Metschnikowiaceae). The nucleotide sequences of 36 fungal taxa were analysed with respect to their molecular evolution and phylogenetic relationships. A total of $460 \mathrm{bp}(47 \%)$ of the coding $979 \mathrm{bp}$ were variable and $396 \mathrm{bp}(\mathbf{4 0} \%)$ of these were found to be phylogenetically informative. Further analysis of the sequences showed that the genic $G+C$ contents were higher than the nuclear $G+C$ contents for most of the taxa. A strong positive correlation was found between $G+C$ content over all codon positions and third positions. First and second codon positions were considered to be independent of the genic G+C content. The expected transition/transversion bias was detected only for third positions. Pairwise comparisons of transitional and transversional changes (substitutions) with total percentage sequence divergences revealed that the third position transitions showed no saturation for ingroup comparisons. A specific weighting scheme was set up, combining codon-position weights with changefrequency weights to enable the inclusion of distant outgroup taxa. Parsimony analyses of the investigated taxa showed four groups, three of which corresponded to major clusters that had been established previously in Candida by rDNA analysis. Interrelationships among the species groups in this heterogeneous anamorphic genus were determined. The polyphyletic origin of the selected Candida species and their close associations with several ascomycete genera were verified and known anamorph/teleomorph pairs confirmed. The actin gene was established as a valuable phylogenetic marker with the particular advantage of an unambiguous alignment.
\end{abstract}

Keywords: Candida, ascomycetous yeasts, phylogeny, actin, molecular evolution

\section{INTRODUCTION}

The phylogenetic results of molecular data sets for single genetic loci have to be treated as gene trees, displaying relationships among the species only for the locus that was sequenced (Fitch, 1996). As the only established phylogenies for Candida and related species

Abbreviations: $\mathrm{Cl}$, consistency index; Co-Q, coenzyme $\mathrm{Q}$ system or ubiquinone; RI, retention index.

The GenBank accession numbers for the nucleotide sequences reported in this paper are AJ389057-AJ389092. have been based on rDNA sequences, distinguishing the overall phylogenetic relationship between the species has not been possible. Given the lack of phylogenetically useful phenotypic characters in the anamorphic genus Candida (Meyer et al., 1998; Starmer et al., 1978; Kurtzman, 1984; Fuson et al., 1980; Price et al., 1978), a well-based species tree should ideally be composed from several gene trees containing all relevant species. We regard this study as a contribution towards this aim. The highly conserved actin gene had the advantage of allowing an unambiguous alignment compared with rDNA se- 
quences, which may be difficult to align with confidence. It had, however, the corresponding disadvantage of yielding relatively few informative characters.

Asexual stages (anamorphs) of ascomycetous species have traditionally been classified in the genus Candida within the artificial form class Deuteromycetes. Their sexual counterparts (teleomorphs) are classified in the Hemiascomycetes according to their ascospores, which are not enclosed in fruiting bodies. Molecular techniques now provide an opportunity to formulate a more natural taxonomy for Candida species that may not be associated directly with a known teleomorph. Existing sequencing studies used to investigate the systematics and phylogeny of Candida species and their teleomorphs are based on the small-subunit rRNA gene (e.g. Barns et al., 1991; Berbee \& Taylor, 1992; Cai et al., 1996) and the 5' end of the largesubunit rRNA gene (e.g. Kurtzman \& Robnett, 1998) or both (e.g. Mendonça-Hagler et al., 1993; Kurtzman \& Robnett, 1994; Yamada et al., 1994) as well as rDNA spacer sequences (Lott et al., 1993; Montrocher et al., 1998). Because of frequently observed limitations of rDNA sequence analysis, such as alignment ambiguity and poorly resolved phylogenetic trees, the actin (act-1) gene was used in this study as a potentially independently evolving marker.

Actins are highly conserved structural proteins, found in all eukaryotes. They are necessary for the transformation of chemical into mechanical energy (Sheterline \& Sparrow, 1994). Within the multigene family, cytoplasmic and muscular actins can be distinguished. Only the cytoplasmic actins are relevant to yeasts. They are involved in various essential cellular functions, including mitosis, and are major proteins within the cytoskeletal structure. Cytoplasmic actin genes are among the most heavily transcribed genes (Lloyd \& Sharp, 1992). As many as five actin genes, encoding different isoforms, have been found in Saccharomyces cerevisiae (Huang et al., 1996). Four of these genes encode so-called 'actin-related' proteins, showing $24-47 \%$ similarity to conventional actin, encoded by the act-1 gene. The conventional actins of Candida albicans and Filobasidiella neoformans, fungi belonging to different phyla, show a high homology of $86 \%$ (Cox et al., 1995). The act- 1 genes consist of a coding region of about $1200 \mathrm{bp}$ and intervening sequences. In contrast to those found in other eukaryotic species, fungal act-1 genes are found as a single copy in each haploid genome. Species in which this status has been confirmed include Candida albicans (Losberger \& Ernst, 1989), Saccharomyces cerevisiae (Gallwitz \& Sures, 1980; Ng \& Abelson, 1980), Schizosaccharomyces pombe (Mertins \& Gallwitz, 1987), Kluyveromyces lactis (Deshler et al., 1989) and Filobasidiella neoformans (Cox et al., 1995).

The actin gene has been used successfully to determine phylogenetic relationships among a number of eukaryotes (Bhattacharya et al., 1991; Bhattacharya \& Ehlting, 1995; Drouin et al., 1995; Bouget et al., 1995), including certain fungi (Cox et al., 1995; Wery et al., 1996). Some of these studies demonstrated that actin gene sequences do not show an independent evolution of characters on all hierarchical levels. As this is one of the central assumptions for phylogenetic analyses, some details of the molecular evolution were investigated. Base composition, transition and transversion rates and mutational saturation were determined and the distribution of these characteristics was analysed according to the codon position, that is, first, second or the more variable third position. From these analyses, different weighting schemes were developed and were compared with an analysis of deduced amino acid sequences. The weights assigned to the codon positions were based on the premise that more conserved characters are more reliable for detection of phylogenetic relationships (Farris, 1966; Kluge \& Farris, 1969).

The purpose of this study was to determine the phylogenetic relationships evidenced by yeast actins and to compare these relationships with those elucidated previously in phylogenetic comparisons of rDNA sequences. The study concentrated on commensal or free-living, opportunistic pathogenic species and was restricted to members of the anamorphic genus Candida and seven teleomorphic genera (Debaryomyces, Issatchenkia, Kluyveromyces, Saccharomyces and Pichia from the Saccharomycetaceae; Clavispora and Metschnikowia from the Metschnikowiaceae). The diversity of ascomycetous yeasts and the wide distribution of Candida anamorphs among them made the inclusion of very distantly related outgroup species necessary. Outgroup species chosen included Neurospora crassa, a member of the Euascomycetes, and Schizosaccharomyces pombe, a member of the Archaeascomycetes. The former fungal class is the most closely related group at this taxonomic level to the Hemiascomycetes, which contains the main group of species tested, while the latter class is basal to both of these groups (Hendriks et al., 1992; Liu et al., 1999). A significantly more distantly related group, the Basidiomycetes, was represented by Filobasidiella neoformans.

\section{METHODS}

Yeast strains, cultivation and identification. The strains examined in this study are listed with their sources in Table 2. All strains were grown on Sabouraud's agar $(10 \mathrm{~g}$ mycological peptone $1^{-1}, 40 \mathrm{~g}$ glucose $1^{-1}, 15 \mathrm{~g}$ agar $1^{-1}$; $\mathrm{pH}$ $5.6 \pm 0.2$ ) at $27^{\circ} \mathrm{C}$ with the exception of Candida lambica and Pichia fermentans, which were grown at $22{ }^{\circ} \mathrm{C}$. The strains were maintained as water cultures at room temperature. Isolates were identified prior to DNA extraction by two carbohydrate assimilation tests: Vitek YBC and API ID 32C (both bioMérieux). The samples were also characterized by their unique PCR fingerprints (Meyer et al., 1997) directly after DNA extraction and again after the sequencing work was finished, to ensure that no sample transposition or contamination had occurred.

DNA sequence determination. Genomic DNA was isolated as described by Meyer et al. (1997). Fragments of the actin 
gene were amplified using two PCR programs. The first consisted of 30 cycles of denaturation at $94{ }^{\circ} \mathrm{C}$ for $3 \mathrm{~min}$ in cycle 1 and $2 \mathrm{~min}$ in cycles $2-30$, annealing at $55^{\circ} \mathrm{C}$ for $2 \mathrm{~min}$ and extension at $72{ }^{\circ} \mathrm{C}$ for $2 \mathrm{~min}$, followed by a final extension at $72^{\circ} \mathrm{C}$ for $10 \mathrm{~min}$ (Kan, 1993). The second, developed by us for the amplification of rDNA fragments, consisted of an initial denaturation for $3 \mathrm{~min}$ at $97^{\circ} \mathrm{C}, 20$ cycles of denaturation at $97^{\circ} \mathrm{C}$ for $35 \mathrm{~s}$, annealing at $50{ }^{\circ} \mathrm{C}$ for $55 \mathrm{~s}$ and extension at $72{ }^{\circ} \mathrm{C}$ for $45 \mathrm{~s}$ (increased by $4 \mathrm{~s}$ per cycle), 10 cycles of denaturation at $97^{\circ} \mathrm{C}$ for $45 \mathrm{~s}$, annealing at $50{ }^{\circ} \mathrm{C}$ for $55 \mathrm{~s}$ and extension at $72{ }^{\circ} \mathrm{C}$ for 2 min (increased by $4 \mathrm{~s}$ per cycle), followed by a final extension at $72^{\circ} \mathrm{C}$ for $6 \mathrm{~min}$. Initial amplifications were performed with the following primer sequences used by Kan (1993). Numbers in parentheses indicate the position of the primer sequence relative to the Candida albicans sequence, GenBank accession no. X16377; the first base of the start codon is base 1. The suffix $\mathrm{R}$ indicates reverse primers, and all primer sequences are given in the $5^{\prime} \rightarrow 3^{\prime}$ direction: CA1, GCCGGTGACGACGCTCCAAGAGCTG (721-745); CA2R, CCGTGTTCAATTGGGTATCTCAAGGTC (852-878); CA3, GACATCAAGGTATCATGGTTGGTATGGGTGC (773-802); CA4, CCATCATGAAGTGTGACATGGATGTTAG, (1499-1526) and CA5R, GTGAACAATGGATGGACCAGATTCGTCG (1743-1770). Additional primers were designed based on the generated sequence: CA7R, CCATCACCAGAATCCAAAACAATACCGG (1103-1130); CA8, TGTACTCTTCTGGTAGAACTACCGG (1082-1106); CA9R, GGTCAATACCAGCAGCTTCCAAACCT (1458-1483); CA11, AACAATGGACGGTGGTATGT (-3-16); CA13, CCAGATGGTCAAGTTATCAC (1384-1403); CA14, AACTGGGATGACATGGAGAAGATCTGGC (889-916); CA15R, TCGGTCAAATCTCTACCAGC (1198-1217); CA16, TTTACGCTGGTTTCTCCATGCCTCACGG (1151-1178) and CA17R, TTGTGGTGAACAATGGATGGACC (1753-1775). Most of the fragments were amplified with the combination of primers CA1 and CA5R. However, the use of CA3, CA8, CA9R, CA11, CA14 and CA17R was necessary to amplify specific fragments for some species. Amplification reactions were performed in $50 \mu \mathrm{l}$ containing $25 \mathrm{ng}$ genomic DNA, $10 \mathrm{mM}$ Tris/ $\mathrm{HCl} \mathrm{pH} \mathrm{8.3,} 50 \mathrm{mM} \mathrm{KCl}, 1.5 \mathrm{mM} \mathrm{MgCl} 2,0 \cdot 2 \mathrm{mM}$ each of dATP, dCTP, dGTP, dTTP (Boehringer), $3 \mathrm{mM}$ magnesium acetate, $50 \mathrm{ng}$ each of the two primers and $2.5 \mathrm{U}$ AmpliTaq Polymerase (Perkin Elmer), using a Perkin Elmer thermal cycler, model 480. Amplification products were assayed by electrophoresis in $0.8 \%$ agarose gels in Tris/ borate buffer and detected by staining with ethidium bromide. These fragments were purified using the Wizard PCR preparation system (Promega). Direct cycle sequencing of PCR products was performed with an automatic sequencer 373A, version 1.2.1 (Applied Biosystems). Both DNA strands were sequenced for all strains. The sequencing reactions contained $100-150 \mathrm{ng}$ amplified fragment, $10 \mathrm{pmol}$ of the appropriate primer $\mu 1^{-1}$ and the ABI PRISM Dye Terminator cycle sequencing ready reaction kit with AmpliTaq DNA polymerase FS (Applied Biosystems). Partial sequences were assembled and aligned manually using the sequence editor SeqPup versions 0.4 and 0.6d (Gilbert, 1996). The reading frames were determined by comparison with published actin gene sequences (e.g. Candida albicans, X16377, and Kluyveromyces lactis, M25826).

Phylogenetic analyses. The numbers of variable sites and sites informative in parsimony analysis and the genic $\mathrm{G}+\mathrm{C}$ content were calculated with the computer program
MaCClade 3.07 (Maddison \& Maddison, 1997). The genic $\mathrm{G}+\mathrm{C}$ contents for first, second and third codon positions were determined separately and plotted against the total $\mathrm{G}+\mathrm{C}$ content of the sequences according to Bhattacharya \& Ehlting (1995). Distance matrices were generated with the programs MEGA 1.01 (Kumar et al., 1993) and PAUP 3.1.1 (Swofford, 1993).

The base composition and the numbers of transitions and transversions for all pairwise comparisons of taxa were calculated using MEGA. The numbers of transitions and transversions partitioned by codon positions were plotted against the total percentage difference (or ' $p$-distance', the number of nucleotide differences divided by the total number of nucleotides; Kumar et al., 1993) in order to determine mutational saturation (Johnson \& Sorenson, 1998).

Random searches were performed using PAUP to evaluate the shape of tree length distributions, represented by their $\mathrm{g} 1$ statistic. The mean tree lengths and their standard deviations were recorded and compared with the length of the most parsimonious trees. PAUP did not allow random searches for the weighted data sets.

Maximum-parsimony trees were constructed for the deduced amino acid data set, the complete nucleotide data set and the data partitioned by codon positions, using heuristic searches with simple and random sequence additions in PAUP. Only the most distant outgroup taxon, Filobasidiella neoformans, was predefined in PAUP as outgroup, to test whether the remaining outgroup species would appear in their expected order relative to the ingroup. When more than one tree was found, the $50 \%$ majority consensus tree was generated.

Because of the frequent occurrence of third position transitions, they were excluded by recoding third codon positions into purines and pyrimidines. Weighting according to the relative substitution frequency of nucleotide changes within each codon position was applied to the complete data set, as well as to the partitioned and the combined data sets. The weights were generated using the 'character steps/etc.' option in the chart menu of the tree window for charting character statistics in MACCLADE. In order to generate weights (scale 1-10) according to codon position, the number of fixed mutational steps $(S)$ attributable to first, second and third codon positions was calculated using the trees derived from unweighted analysis of all coding characters. Weights $(W)$ were generated using the formula $W=1 / S$. Weights of 4, 10 and 1 were obtained for first, second and third positions, respectively. Similar analysis of the pooled data for first and second positions resulted in weights of 1 for first and 10 for second positions. Weights corresponding to the relative frequency of nucleotide changes (change-frequency weighting) at each individual position were obtained by calculating the number of changes at that position. The same MACClADE menu and options were used as for the assignment of weights to the codon positions. The calculation of these weights was performed using the trees derived from unweighted analyses of separate codon positions. The resulting weights ranged from 1 to 10 . Combined weights incorporating both change frequency and codon position were obtained by multiplying the weights of the two separate factors for each position. For instance, a first position with a calculated change-frequency weight of 10 was given the combined weight of 40 after multiplying by 4 , the weight of the corresponding (i.e. the first, as mentioned above) codon position.

PAUP was used to conduct bootstrap analyses (Felsenstein, $1985)$ with 100 replicates for all phylogenies. In addition, 
1000 replicates were performed for selected phylogenies. Bootstrap values above 70 were considered significant in the sense of demonstrating repeatability as suggested by Hillis \& Bull (1993). This was based on the premise that the weighting technique we used neutralizes the effect of unequal rates of evolution as much as possible.

The MACCLADE program was used to generate consistency indices (CI) as a measurement of homoplasy (Kluge \& Farris, 1969) after exclusion of uninformative characters. CI is 1 for a given data set when there is no homoplasy and decreases as homoplasy increases. However, the CI is known to be negatively correlated with the number of taxa and characters (Goloboff, 1991). The retention indices (RI, with a possible range of 0 to 1 ) were also evaluated in MACCLADE, to express the data-tree fit as the amount of synapomorphy in the data sets (Farris, 1989). The RI is high when changes occur predominantly on internal branches and low when changes are concentrated on branches leading to terminal taxa. CI and RI are useful for comparing different trees generated from one data matrix (Goloboff, 1991) and were used to assess the value of the different weighting methods and schemes.

\section{RESULTS}

\section{Sequence alignment and variation}

An alignment of 39 partial sequences of the actin gene was analysed (EMBL alignment number DS : 39430). Each sequence comprised $1127 \mathrm{bp}$. The sequence of the most distant outgroup taxon, Filobasidiella neoformans, contained introns of $148 \mathrm{bp}$, necessitating the insertion of three gaps of $46-51 \mathrm{bp}$. In all taxa analysed, including outgroups, $460 \mathrm{bp}(47 \%)$ of the coding 979 bp were variable and 396 bp (40\%) proved to be phylogenetically informative (Table 1).

In order to gauge the effectiveness with which the taxa were separated, we looked at the range of sequence variability among the taxa analysed. The highest intergeneric variability $(31.4 \%$, data not shown; distance matrix available on request) was found between Filobasidiella neoformans and Pichia/Candida norvegensis. The lowest (20.6\%) occurred between Schizosaccharomyces pombe and Clavispora opuntiae. The variability within the ingroup ranged from $22.2 \%$ for the distantly related Candida species Candida zeylanoides and Pichia/Candida norvegensis to $2 \cdot 1 \%$ for the closely related species Candida albicans and Candida dubliniensis. The intraspecies variability ranged from $0.4 \%$ for Metschnikowia pulcherrima and Candida pulcherrima to no variability between Kluyveromyces lactis and Candida sphaerica or the two strains of Candida glabrata, WM 53 and WM 54.

\section{$\mathbf{G}+\mathbf{C}$ content}

The genic $\mathrm{G}+\mathrm{C}$ contents of the actin sequences were determined and compared with the overall nuclear $\mathrm{G}+\mathrm{C}$ content (Table 2). The genic $\mathrm{G}+\mathrm{C}$ contents were slightly higher than the nuclear $\mathrm{G}+\mathrm{C}$ content for most taxa. The $\mathrm{G}+\mathrm{C}$ content in third codon positions was positively correlated with the overall $\mathrm{G}+\mathrm{C}$ content (Fig. 1). First codon position $\mathrm{G}+\mathrm{C}$ contents were partially correlated with the total genic $\mathrm{G}+\mathrm{C}$ content, as only the three outgroup species showed first position values higher than the mean. This is also shown by differences in the linear regression for comparisons including $\left(r^{2}=0.312\right)$ and excluding $\left(r^{2}=0 \cdot 141\right)$ the outgroup species. Second codon position $\mathrm{G}+\mathrm{C}$ contents were not correlated with the overall $\mathrm{G}+\mathrm{C}$ content.

\section{Base composition and transition/transversion rates}

The mean base composition of the actin sequences was biased in each of the three codon positions. There was an overrepresentation of adenine $(30.6 \%)$ and guanine $(32.4 \%)$ in first positions, adenine $(29.7 \%)$ and thymine $(30.2 \%)$ in second positions and thymine $(33.9 \%)$ and cytosine $(28.1 \%)$ in third positions. Lower representation was recorded for cytosine $(13.5 \%)$ in first positions, guanine $(14.9 \%)$ in second positions and guanine $(17 \cdot 4 \%)$ in third positions. The pattern of variation at first and second positions was not significantly different between species, as shown by the standard deviations for first positions $(0 \cdot 37-2 \cdot 83)$ and for second positions $(0 \cdot 4-0 \cdot 6)$. The standard deviations for third positions $(5 \cdot 3-8 \cdot 8)$ indicate significant differences between the species compared.

Transitions accounted for a mean of $70 \%$ of changes in the ingroup comparisons and $56 \%$ in the ingroupoutgroup comparisons. The portions of transitions in first, second and third codon positions for comparisons at the ingroup/outgroup levels were $4 / 10,2 / 2$ and $64 / 43 \%$, respectively. About three times more transitions than transversions were detected in third positions and about twice as many transversions than transitions in first and second positions. The number of transitions and transversions continued to increase at higher divergences ( $p$-distances) in the first and second positions; only transversions increased in third positions (Fig. 2). The number of third position transitions was not significantly higher in the ingroupoutgroup comparisons (mean 81.2, standard deviation 21.4 ) than in the ingroup-ingroup comparisons (mean $102 \cdot 1$, standard deviation $15 \cdot 2$ ). Closer examination of the transitions at third positions within the ingroup revealed that the largest numbers were accumulated by the comparison of the distantly related ingroup species Saccharomycopsis capsularis and Pichia/Candida norvegensis. The largest numbers of third position transitions were found in comparisons involving taxa with deviating $\mathrm{G}+\mathrm{C}$ contents, e.g. Pichia/Candida norvegensis (lowest genic $\mathrm{G}+\mathrm{C}$ content of $32.9 / 33 \%$ ) and Candida zeylanoides (highest genic $\mathrm{G}+\mathrm{C}$ content for all ingroup species of $50 \cdot 5 \%$ ) (Table 2).

\section{Phylogenetic signal and comparative analysis}

The g1 values of the tree-length distributions were determined for the unweighted data sets (Table 1). They were below the critical values proposed by Hillis \& Huelsenbeck (1992) for all combinations of characters, indicating the presence of a phylogenetic signal in all data sets. The heuristic search identified par- 
Table 1. Comparison of character information content for different data sets, frequency distribution of 10000 randomly sampled tree lengths and measures of fit statistics for most parsimonious trees generated by heuristic search

SD, Standard deviation; - , not evaluated; +, soft polytomies underestimate.

\begin{tabular}{|c|c|c|c|c|c|c|c|c|c|c|}
\hline \multirow[t]{2}{*}{ Characters (total of $1127 \mathrm{bp}$ ) } & \multicolumn{3}{|c|}{ Character information content } & \multicolumn{3}{|c|}{ Random search } & \multicolumn{4}{|c|}{ Heuristic search } \\
\hline & Total & Variable & Informative & $\begin{array}{l}\text { Mean tree } \\
\text { length }\end{array}$ & SD & g1 & $\mathrm{CI}^{*}$ & RI & Tree length* & Number of trees \\
\hline Deduced amino acid sequence & 326 & 94 & 62 & 399 & $10 \cdot 5$ & -0.54 & 0.72 & $0 \cdot 86$ & $144+$ & 30 \\
\hline $\begin{array}{l}\text { All coding residues } \\
\text { All coding residues weighted according to: }\end{array}$ & 979 & 460 & 396 & 3379 & $63 \cdot 7$ & $-0 \cdot 71$ & $0 \cdot 34$ & $0 \cdot 63$ & $1776+$ & 3 \\
\hline $\begin{array}{l}\text { Codon position } \\
\text { Change frequencies } \\
\text { Codon position and change frequencies }\end{array}$ & $\begin{array}{l}979 \\
979 \\
979\end{array}$ & $\begin{array}{l}460 \\
460 \\
460\end{array}$ & $\begin{array}{l}396 \\
396 \\
396\end{array}$ & $\begin{array}{l}- \\
- \\
-\end{array}$ & $\begin{array}{l}- \\
- \\
-\end{array}$ & $\begin{array}{l}- \\
- \\
-\end{array}$ & $\begin{array}{l}0 \cdot 44 \\
0 \cdot 46 \\
0 \cdot 57\end{array}$ & $\begin{array}{l}0 \cdot 7 \\
0 \cdot 7 \\
0 \cdot 79\end{array}$ & $\begin{array}{l}2842+ \\
3928+ \\
7946+\end{array}$ & $\begin{array}{l}1 \\
1 \\
1\end{array}$ \\
\hline $\begin{array}{l}\text { 1st positions } \\
\text { 2nd positions } \\
\text { 3rd positions } \\
\text { 3rd transversions only }\end{array}$ & $\begin{array}{l}326 \\
326 \\
327 \\
327\end{array}$ & $\begin{array}{r}111 \\
52 \\
297 \\
147\end{array}$ & $\begin{array}{r}81 \\
29 \\
286 \\
127\end{array}$ & $\begin{array}{r}493 \\
159 \\
2727 \\
639\end{array}$ & $\begin{array}{r}12 \cdot 1 \\
5 \cdot 2 \\
54 \cdot 4 \\
15\end{array}$ & $\begin{array}{l}-1 \\
-0 \cdot 39 \\
-0 \cdot 74 \\
-1 \cdot 19\end{array}$ & $\begin{array}{l}0 \cdot 58 \\
0 \cdot 71 \\
0 \cdot 31 \\
0 \cdot 45\end{array}$ & $\begin{array}{l}0 \cdot 79 \\
0 \cdot 88 \\
0 \cdot 61 \\
0 \cdot 72\end{array}$ & $\begin{array}{r}189+ \\
49+ \\
1500+ \\
280+\end{array}$ & $\begin{array}{r}255 \\
1460 \\
1 \\
400\end{array}$ \\
\hline $\begin{array}{l}\text { 1st and 2nd positions } \\
1 \text { st and 2nd positions weighted according to: }\end{array}$ & 652 & 163 & 110 & 653 & 16 & $-0 \cdot 81$ & $0 \cdot 6$ & $0 \cdot 8$ & $242+$ & 22 \\
\hline $\begin{array}{l}\text { Codon position } \\
\text { Change frequencies } \\
\text { Codon position and change frequencies }\end{array}$ & $\begin{array}{l}652 \\
652 \\
652\end{array}$ & $\begin{array}{l}163 \\
163 \\
163\end{array}$ & $\begin{array}{l}110 \\
110 \\
110\end{array}$ & $\begin{array}{l}- \\
- \\
-\end{array}$ & $\begin{array}{l}- \\
- \\
-\end{array}$ & $\begin{array}{l}- \\
- \\
-\end{array}$ & $\begin{array}{l}0 \cdot 67 \\
0 \cdot 78 \\
0 \cdot 83\end{array}$ & $\begin{array}{l}0 \cdot 85 \\
0 \cdot 9 \\
0 \cdot 93\end{array}$ & $\begin{array}{r}688+ \\
8559+ \\
29782+\end{array}$ & $\begin{array}{r}203 \\
24 \\
30\end{array}$ \\
\hline $\begin{array}{l}1 \text { st and } 2 \text { nd positions and } 3 \text { rd transversions } \\
1 \text { st and } 2 \text { nd positions and } 3 \text { rd transversions weighted according to: }\end{array}$ & 979 & 490 & 237 & 1292 & $28 \cdot 2$ & -1.09 & $0 \cdot 5$ & $0 \cdot 74$ & $540+$ & 24 \\
\hline $\begin{array}{l}\text { Codon position } \\
\text { Change frequencies } \\
\text { Codon position and change frequencies }\end{array}$ & $\begin{array}{l}979 \\
979 \\
979\end{array}$ & $\begin{array}{l}490 \\
490 \\
490\end{array}$ & $\begin{array}{l}237 \\
237 \\
237\end{array}$ & $\begin{array}{l}- \\
- \\
-\end{array}$ & $\begin{array}{l}- \\
-\end{array}$ & $\begin{array}{l}- \\
- \\
-\end{array}$ & $\begin{array}{l}0.65 \\
0.69 \\
0.8\end{array}$ & $\begin{array}{l}0 \cdot 84 \\
0 \cdot 85 \\
0 \cdot 9\end{array}$ & $\begin{array}{r}7792+ \\
19622+ \\
28840+\end{array}$ & $\begin{array}{r}16 \\
4 \\
4\end{array}$ \\
\hline
\end{tabular}

* After exclusion of uninformative residues. 
Table 2. Grouping of Candida species with related teleomorphs and outgroup species according to phylogenetic analysis of partial actin gene sequences

Abbreviations: NA, not available; BD, buoyant density in caesium salt gradients.

\begin{tabular}{|c|c|c|c|c|}
\hline \multirow[t]{2}{*}{ Species } & \multirow[t]{2}{*}{ Strain* } & \multirow{2}{*}{$\begin{array}{c}\text { Co-Q } \\
\text { system } \dagger\end{array}$} & \multicolumn{2}{|c|}{$G+C$ content $(\mathrm{mol} \%)$} \\
\hline & & & Nuclear DNA $\dagger$ & $\begin{array}{l}\text { Partial actin } \\
\text { gene sequence }\end{array}$ \\
\hline \multicolumn{5}{|l|}{ Group A } \\
\hline Candida albicans & CBS $562^{\mathrm{NT}}$ & 9 & $34 \cdot 9-37 \cdot 3$ & $38 \cdot 1$ \\
\hline Candida dubliniensis & CBS $7987^{\mathrm{T}}$ & $\mathrm{NA}$ & $35 \cdot 4-36 \cdot 8 \div$ & $39 \cdot 4$ \\
\hline Candida tropicalis & DUMC 29-3711 & 9 & $33 \cdot 2-36 \cdot 1$ & $39 \cdot 9$ \\
\hline Candida maltosa & CBS $5611^{\mathrm{T}}$ & 9 & $35 \cdot 6-36 \cdot 8$ & $39 \cdot 7$ \\
\hline Candida viswanathii & CBS $4024^{\mathrm{T}}$ & $9^{a}$ & $45 \cdot 6-46 \cdot 3$ & $44 \cdot 3$ \\
\hline Candida parapsilosis & DUMC 31-1070 & 9 & $39 \cdot 3-40 \cdot 8$ & $40 \cdot 2$ \\
\hline \multicolumn{5}{|l|}{ Group B } \\
\hline Pichia guilliermondii/Candida guilliermondii & CBS $2030^{\mathrm{T}} / \mathrm{CBS} 566^{\mathrm{T}}$ & 9 & $44 \cdot 4(\mathrm{BD}) ; 44 \cdot 6$ & $46 \cdot 6 / 46 \cdot 7$ \\
\hline Candida zeylanoides & CBS $619^{\mathrm{NT}}$ & 9 & $54 \cdot 4-57 \cdot 6$ & $50 \cdot 5$ \\
\hline Debaryomyces etchellsii & CBS $2011^{\mathrm{T}}$ & 9 & $38 \cdot 5 ; 40 \cdot 6$ (BD) & $43 \cdot 2$ \\
\hline Metschnikowia pulcherrima/Candida pulcherrima & CBS $2255^{\mathrm{T}} / \mathrm{CBS} 610^{\mathrm{NT}}$ & 9 & $45 \cdot 6(\mathrm{BD})$ & $47 \cdot 7 / 47 \cdot 8$ \\
\hline Clavispora lusitaniae/Candida lusitaniae & CBS $6936^{\mathrm{T}} / \mathrm{CBS} 4413^{\mathrm{T}}$ & 8 & $45 \cdot 1$ (BD) $-45 \cdot 7$ (BD) & $48 \cdot 1$ \\
\hline Clavispora opuntiae & CBS $7068^{\mathrm{T}}$ & 8 & $43 \cdot 1(\mathrm{BD})-44 \cdot 1(\mathrm{BD})$ & $44 \cdot 6$ \\
\hline \multicolumn{5}{|l|}{ Group C } \\
\hline Candida glabrata & DUMC $19-1112 /$ CBS $138^{\mathrm{T}}$ & 6 & $38 \cdot 5-40 \cdot 2$ & 45 \\
\hline Saccharomyces kluyveri & CBS $3082^{\mathrm{T}}$ & 6 & $41 \cdot 9$ & $43 \cdot 1$ \\
\hline Kluyveromyces polysporus & CBS $2163^{\mathrm{T}}$ & $6^{b}$ & $35 \cdot 3$ (BD) & $43 \cdot 1$ \\
\hline Saccharomyces cerevisiae/Candida robusta & CBS $1171^{\mathrm{NT}} / \mathrm{CBS} 1907^{\mathrm{T}}$ & 6 & $38 \cdot 5-41 \cdot 1$ & $43 \cdot 4 / 43 \cdot 5$ \\
\hline Kluyveromyces marxianus/Candida kefyr & CBS $712^{\mathrm{T}} / \mathrm{CBS} 834^{\mathrm{T}}$ & 6 & $41 \cdot 1-41 \cdot 5(\mathrm{BD})$ & $43 / 43 \cdot 2$ \\
\hline Kluyveromyces lactis/Candida sphaerica & $\mathrm{CBS} 683^{\mathrm{NT}} / \mathrm{CBS} 141^{\mathrm{T}}$ & 6 & $39 \cdot 9-40 \cdot 8(\mathrm{BD})$ & $44 \cdot 3$ \\
\hline \multicolumn{5}{|l|}{ Group D } \\
\hline Pichia fermentans / Candida lambica & CBS $187^{\mathrm{T}} / \mathrm{CBS} 1876^{\mathrm{T}}$ & 7 & $42 \cdot 2 ; 43 \cdot 1$ & $43 \cdot 7 / 43 \cdot 5$ \\
\hline Pichia norvegensis /Candida norvegensis & CBS $6564^{\mathrm{T}} /$ CBS $1922^{\mathrm{T}}$ & 7 & $35 \cdot 5-37 \cdot 6$ & $33 / 32 \cdot 9$ \\
\hline Issatchenkia orientalis/Candida krusei & CBS $5147^{\mathrm{T}} / \mathrm{CBS} 573^{\mathrm{T}}$ & 7 & $39 \cdot 7-40 \cdot 3$ & $37 \cdot 1$ \\
\hline Pichia membranifaciens/Candida valida & CBS $107^{\mathrm{T}} / \mathrm{CBS} 638^{\mathrm{T}}$ & 7 & $41 \cdot 5-44 \cdot 3$ & $41 \cdot 4 / 41 \cdot 5$ \\
\hline \multicolumn{5}{|l|}{ Ungrouped } \\
\hline Pichia jadinii/Candida utilis & CBS $1600^{\mathrm{T}} / \mathrm{CBS} 621^{\mathrm{T}}$ & 7 & $45 \cdot 1(\mathrm{BD})-45 \cdot 8(\mathrm{BD})$ & $47 / 46 \cdot 7$ \\
\hline Saccharomycopsis capsularis & CBS $2519^{\mathrm{NT}}$ & 8 & $43 \cdot 4$ & $50 \cdot 3$ \\
\hline \multicolumn{5}{|l|}{ Outgroup } \\
\hline Neurospora crassa & - & $\mathrm{NA}$ & $54^{c}$ & $56 \cdot 2$ \\
\hline Schizosaccharomyces pombe & L 975 & 10 & $35 \cdot 1-42$ & $45 \cdot 1$ \\
\hline Filobasidiella neoformans var. neoformans & H 99 & 10 & $53 \cdot 2-56 \cdot 7$ & $52 \cdot 4$ \\
\hline
\end{tabular}

* CBS, Centraalbureau voor Schimmelcultures, The Netherlands; DUMC, Duke University Medical Centre, USA; T, ex-type culture; NT, ex-neotype culture. Strain H 99 was used by Cox et al. (1995); strain L 975 was used by Mertins \& Gallwitz (1997).

$\dagger$ For the species, reviewed by Kurtzman \& Fell (1998) except as indicated by $a$ (CBS database; http://www.cbs.knaw.nl), $b$ (Molnár et al., 1996) or $c$ (Villa \& Storck, 1968).

$\ddagger$ Personal communication, E. O’Neill.

simonious trees that were significantly shorter than the mean length of the random trees.

Amino acid sequences were deduced from nucleotide sequences. Heuristic analysis of these sequences was considered to be the most conservative phylogenetic examination. The tree revealed four major groups of species, subsequently referred to as species groups A, $\mathrm{B}, \mathrm{C}$ and D (Table 2). Groups A and B formed the significantly supported cluster A/B.
The data for individual codon positions were considered separately in further analyses. The ability of these analyses to detect the groups delineated in amino acid analysis is summarized in Table 3 . The comparison of data sets for the first, second and third positions showed that the high variability within the third position was coupled with the lowest CI and RI in all subsets analysed (Table 1). The single tree resulting from the analysis of the third position placed one of the outgroup taxa (Schizosaccharomyces pombe) 


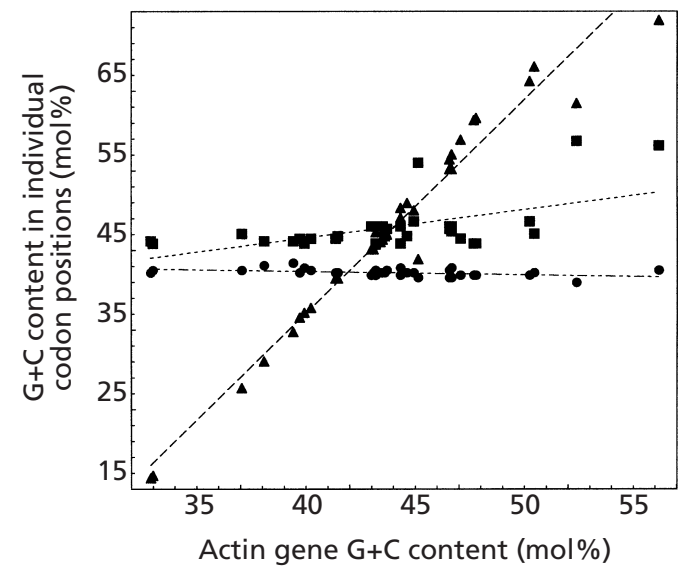

Fig. 1. Correlation of $G+C$ content over all positions with first $(\boldsymbol{\square})$, second $(\boldsymbol{O})$ and third $(\boldsymbol{\Delta})$ positions of actin codons for 39 fungal taxa. The ranges of $\mathrm{G}+\mathrm{C}$ content at each codon position were $43.0-56.7 \mathrm{~mol} \%$ (first), $39.6-41.4 \mathrm{~mol} \%$ (second) and $14.4-71.9 \mathrm{~mol} \%$ (third). The $r^{2}$ values from linear regression for comparisons including/excluding the outgroup species were $0 \cdot 312 / 0 \cdot 141$ (first), 0.202/0.222 (second) and 0.965/0.995 (third).

within the ingroup (data not shown), as sister group to Pichia/Candida guilliermondii, taxa with similar genic $\mathrm{G}+\mathrm{C}$ contents. Separate analyses of the first and third positions showed different interrelationships among groups A, C and D (data not shown). Analysis of the second codon positions divided each of groups B and $\mathrm{C}$ into two neighbouring clades. When the first and second codon positions were analysed together, a lack of informative characters was reflected in short branches and polytomies in groups $\mathrm{C}$ and $\mathrm{D}$.

\section{Phylogeny reconstruction and weighting}

The influences of different weighting schemes on phylogeny reconstruction were investigated. Four types of weights were used: (i) exclusion of third position transitions based on observed transitional bias, (ii) change-frequency weighting based on the assumption that fewer required steps in a character indicate stronger support for a tree, (iii) codonposition weighting as weighting of first, second and third positions in relation to redundancy of the genetic code and (iv) combinations of these. The character information content and statistical analyses for the different data sets under different weighting schemes are summarized in Table 1.

The analyses of third-position transversions alone and in combination with first and second positions detected groups $\mathrm{A}, \mathrm{C}$ and $\mathrm{D}$ (Table 3). However, the interrelationships among these groups differed. These analyses failed to assign some species to any of the groups, but clustered the Clavispora and Metschnikowia species together. The CI and RI values were increased compared with the corresponding analyses involving the complete third positions (Table 1).

Change-frequency weights led to increased CIs and RIs as well as significantly increased bootstrap values in the heuristic searches on all combined data sets compared with their unweighted alternatives. However, the outgroup taxa were not separated in the expected order.

Codon-position weighting led to slightly lower values for CI and RI compared with the change-frequency weighting. Bootstrap values were increased compared with those of the unweighted analyses, but lower when compared with those of the change-frequencyweighted analyses. Analysis of the complete data set transformed by codon-position weighting distinguished group B, while analysis of the unweighted alternative failed to do so (Table 3). This type of weighting applied to the two recombined data sets (first plus second and first plus second plus recoded third positions) separated the outgroup taxa in the expected order.

Analysis of the two recombined data sets using the combined values incorporating both change-frequency and codon-position weights led to similar tree topologies. In the analysis of combined first and second positions, one taxon, Kluyveromyces polysporus, was separated from group $\mathrm{C}$ and appeared as a sister group to it (data not shown). The highest values for CI and RI were detected for the data sets of combined first and second positions and combined first, second and recoded third positions (Table 1). Bootstrap values were decreased compared with those assigned to change-frequency-weighted analyses. Analyses of these data sets showed identical interrelationships of the groups compared with the analysis of the deduced amino acids. However, the tree derived from the three combined positions was chosen for Fig. 3 to represent the complete data set.

\section{Molecular analysis and phylogeny of Candida species}

The basidiomycetous yeast Filobasidiella neoformans, the ascomycetous yeast Schizosaccharomyces pombe and the filamentous ascomycete Neurospora crassa were included as the outgroup taxa to root the trees obtained. Within the four major groups detected in the ingroup (Fig. 3; Table 2), all anamorph/teleomorph relationships were confirmed. Opportunistic pathogens did not cluster into a single group.

The tree including the highly variable third positions was used in order to detect the intragroup relationships (Fig. 3). Within group A, Candida dubliniensis was most closely related to Candida albicans. Candida tropicalis, Candida maltosa and Candida viswanathii were the next most closely related taxa to Candida albicans. Candida parapsilosis appeared basal (closer to the root) to the other species of this group. The Clavispora species formed one clade in group B. The relationships of other members of group B, Pichia/Candida guilliermondii, Debaryomyces etchellsii, Metschnikowia/Candida pulcherrima and Candida zeylanoides could not be resolved. Group C contained a cluster of Kluyveromyces marxianus/Candida kefyr with Kluyveromyces lactis/ 

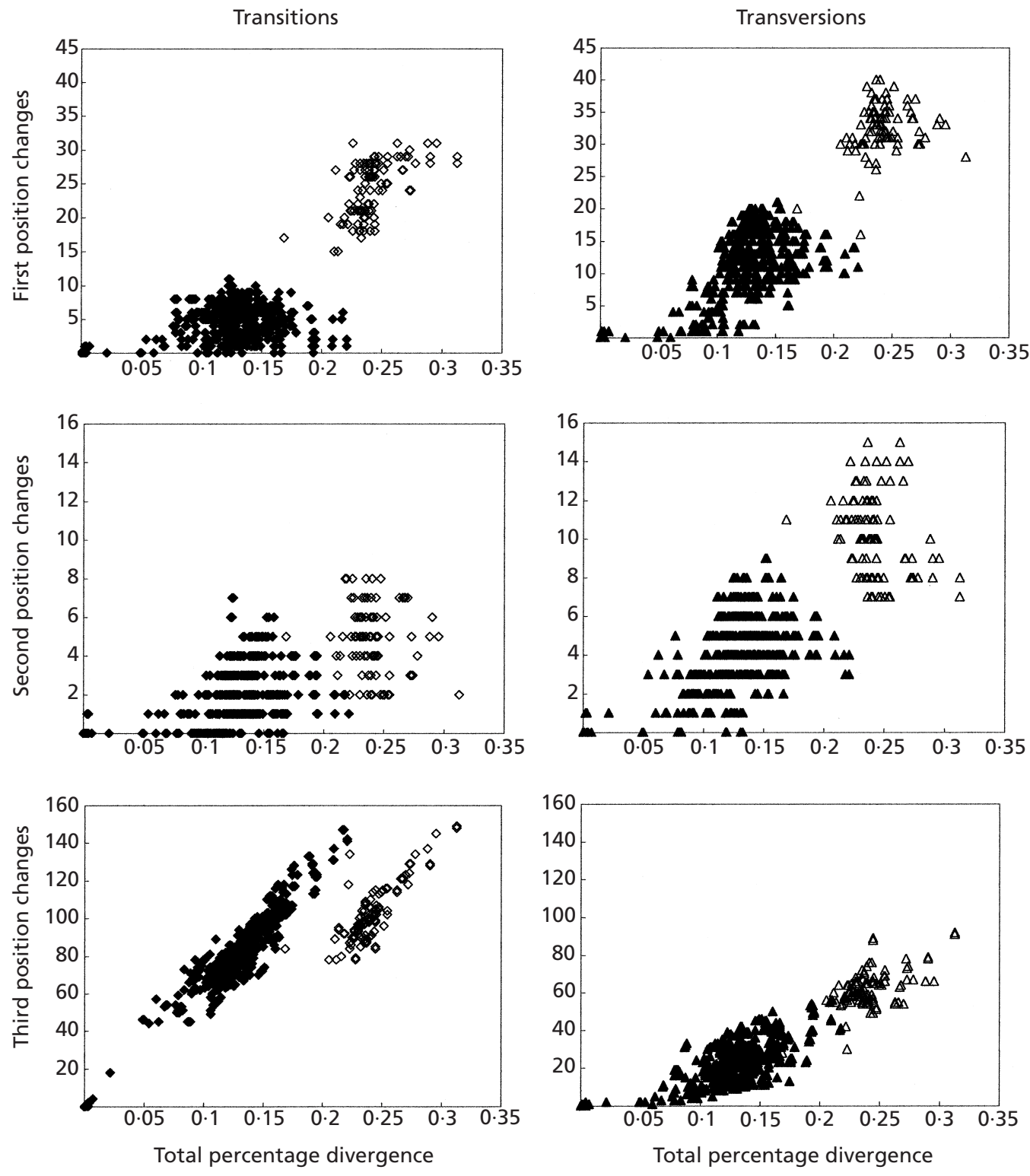

Fig. 2. Plots of pairwise transitional and transversional substitutions against total percentage divergence ( $p$-distance; Kumar et al., 1993) partitioned by codon position. Filled symbols refer to ingroup comparisons, open symbols refer to comparisons of outgroup species as well as to comparisons between ingroup and outgroup species. Diamonds refer to transitions, triangles to transversions.

Candida sphaerica. Kluyveromyces polysporus was basal to Saccharomyces cerevisiae/Candida robusta followed by Candida glabrata and Saccharomyces kluyveri. Group D showed a close relationship between Pichia/Candida norvegensis and Issatchenkia krusei/ Candida orientalis. The relationships within this group could not be resolved further.

The sister-group relationship of groups A and B was resolved by several analyses, including the data set of the first and second codon positions and by the analysis of deduced amino acids (Table 3). Groups C and D were more closely related to the cluster A/B than were Pichia jadinii and Candida utilis. However, the order of these groups relative to the A/B cluster could not be resolved. Groups $\mathrm{C}$ and $\mathrm{D}$ were sister groups in the weighted and unweighted analyses of the complete data set and in the analysis weighted according to the change frequency of first and second positions. Other analyses showed that either species group $\mathrm{C}$ or $\mathrm{D}$ was closer to the A/B cluster, but none of these formations was favoured. Saccharomycopsis capsularis was placed basal to the remainder of the ingroup species.

\section{Tree support}

Bootstrap analyses revealed high support for the anamorph/teleomorph pairs in all analyses, except for 
Table 3. Frequency of recovery of groups $A, B, C$ and $D$ and cluster $A / B$ in 100 bootstrap replicates

\begin{tabular}{|c|c|c|c|c|c|c|}
\hline Characters included & $\mathbf{A}$ & B & $\mathbf{C}$ & $\mathbf{D}$ & $\mathbf{A} / \mathbf{B}$ & Outgroup* \\
\hline Deduced amino acid sequence & 84 & 50 & 45 & 69 & 95 & 82 \\
\hline All coding residues & 73 & - & 57 & 91 & - & - \\
\hline \multicolumn{7}{|l|}{ All coding residues weighted according to: } \\
\hline Codon position & 100 & 71 & 66 & 96 & 76 & - \\
\hline Change frequencies & 99 & 51 & 84 & 100 & 43 & - \\
\hline Codon position and change frequencies & 100 & 85 & 73 & 98 & 87 & 69 \\
\hline 1st positions & 83 & 43 & 52 & 53 & 35 & - \\
\hline 2nd positions & 75 & - & - & 48 & - & 95 \\
\hline 3rd positions & 13 & - & 8 & 47 & - & - \\
\hline 3rd transversions only & 63 & - & 17 & 81 & - & - \\
\hline 1st and 2 nd positions & 95 & 49 & 52 & 70 & 78 & - \\
\hline \multicolumn{7}{|l|}{ 1st and 2 nd positions weighted according to: } \\
\hline Codon position & 98 & 51 & 41 & 70 & 83 & 93 \\
\hline Change frequencies & 96 & 63 & 83 & 92 & 93 & - \\
\hline Codon position and change frequencies & 94 & 53 & 23 & 81 & 90 & 89 \\
\hline 1st and 2 nd positions and 3 rd transversions & 97 & - & 70 & 95 & - & - \\
\hline \multicolumn{7}{|c|}{ 1st and 2 nd positions and 3 rd transversions weighted according to: } \\
\hline Codon position & 100 & 60 & 40 & 85 & 72 & 83 \\
\hline Change frequencies & 100 & - & 91 & 98 & - & - \\
\hline Codon position and change frequencies & 95 & 73 & 47 & 96 & 90 & 94 \\
\hline
\end{tabular}

* Frequency with which the outgroup was detected as expected, that is Neurospora crassa closest to the ingroup while Filobasidiella neoformans was defined as the outgroup.

the two Kluyveromyces pairs, which were insufficiently resolved unless the complete data set, including the third position transitions, was applied (Fig. 3). The separation of the outgroup taxa from the ingroup was supported by significant bootstrap values (generally 70-100). Table 3 details bootstrap support for the groups detected, including the cluster $\mathrm{A} / \mathrm{B}$. The connecting node of groups A and B was supported significantly in most of the analyses that detected group $\mathrm{B}$. The position of groups $\mathrm{C}$ and $\mathrm{D}$ could not be resolved at a significant bootstrap level.

\section{DISCUSSION}

Consideration of variable and informative characters at each of the different codon positions gave insight into the relative contribution of each position to the resolution of the trees that were generated (Table 1). The range of variability allowed us to distinguish intraspecific from interspecific variation. The overlap in levels of genetic divergence for outgroup-ingroup comparisons and some comparisons among ingroup species illustrated the breadth of diversity within the artificial form genus Candida. As most of this sequence variation was concentrated in the third codon position, several tests were carried out separately for this position as well as the other codon positions. Based on analysis of the genic $\mathrm{G}+\mathrm{C}$ content (Fig. 1), the second position evolved independently from the overall $\mathrm{G}+\mathrm{C}$ content and can be used to infer phylogenies for all species. The first position is informative for all ingroup species but not for ingroup-outgroup comparisons. The third position contains useful information for comparisons of species with similar $\mathrm{G}+\mathrm{C}$ content. However, it would be misleading in the detection of phylogenetic relationships for species with deviating $\mathrm{G}+\mathrm{C}$ contents. The detected correlation of the genic $\mathrm{G}+\mathrm{C}$ content with the overall $\mathrm{G}+\mathrm{C}$ content was observed previously in an analysis of actin gene sequences in eukaryotes (Bhattacharya \& Ehlting, 1995). This, together with the biased base composition, is the basis for the application of weights according to codon position in our analysis. The biases detected in base composition at all three positions showed that one of the central assumptions of phylogenetic analysis, the independence of characters, was violated. Even though these positions are biased towards certain bases, the low species-to-species variation seen within this bias permits a valid phylogenetic analysis. Therefore, the compositional biases observed for first and second positions should not interfere with the phylogenetic analysis (Ducroz et al., 1998).

The general bias of transitions over transversions (Brown et al., 1982) was found only for the third position. The more frequent occurrence of transitions has been attributed to misincorporation of bases during replication rather than to other types of mutations. The conserved positions are unlikely to be strongly influenced by misincorporation, because any resulting amino acid changes are highly likely to eliminate functionality, leading to a lethal mutation. This could explain why first and second positions did 


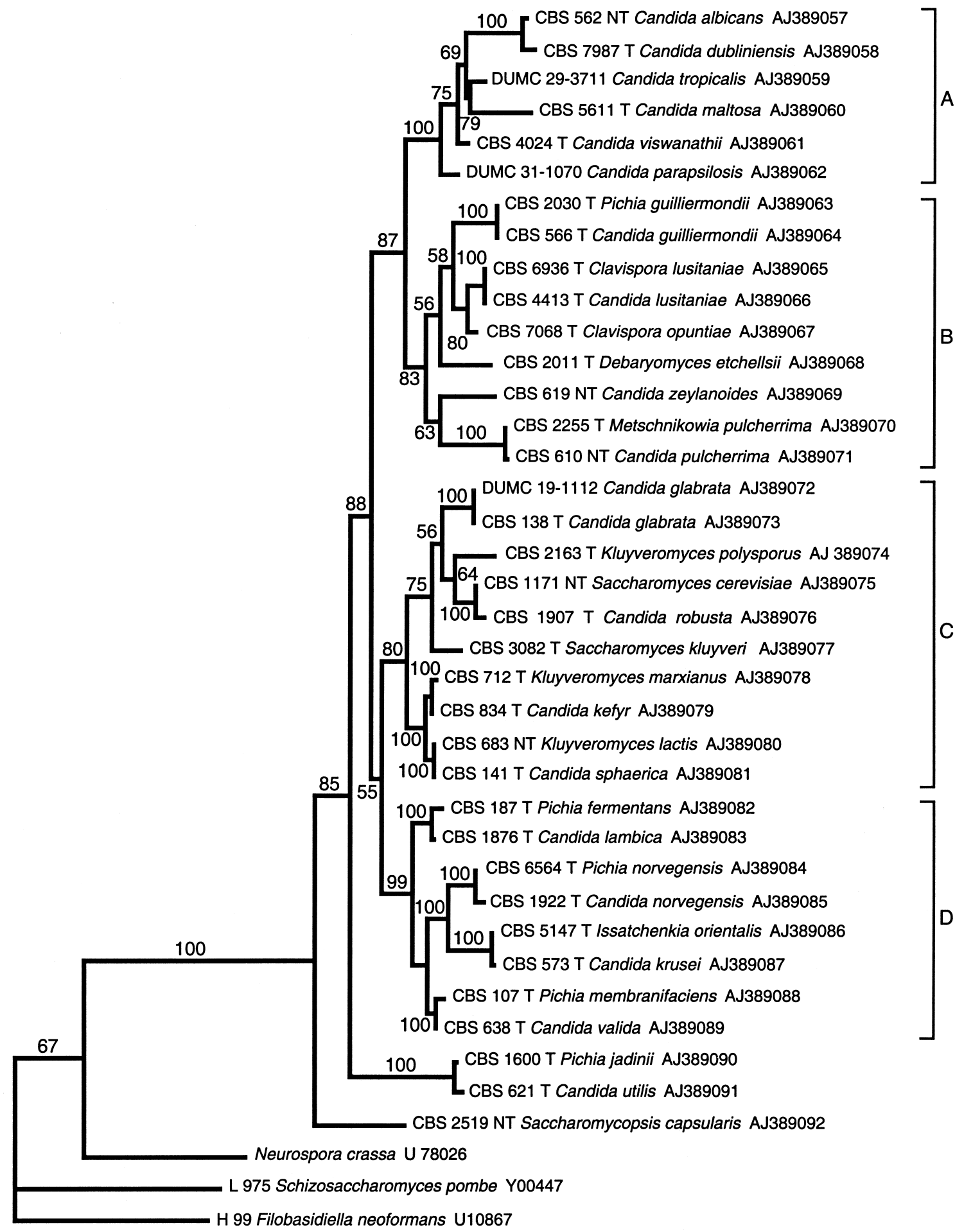

Fig. 3. Phylogenetic tree produced by weighted parsimony analysis of partial sequences of the actin gene from 39 yeast taxa. The tree was derived by a heuristic search (PAUP 3.1.1) from the complete data set of all three codon positions (979 bp), under application of combined weights for the codon positions and for character changes according to their frequency (MACCLADE 3.07). Filobasidiella neoformans was defined as outgroup. Numbers on branches indicate bootstrap values greater than 50 after 1000 replications. This single most parsimonious tree consists of $7946+$ steps (soft polytomies underestimate) and shows the indices $\mathrm{Cl}=0.57$ (excluding uninformative characters) and $\mathrm{RI}=0.79$. 
not follow the predicted transition-transversion bias. However, the reason was not clarified in this study. A level of transitions near $50 \%$ was proposed as an indication that sequences had become saturated with a maximal number of substitutions (Knight \& Mindell, 1993). According to this, the third position transitions are not saturated for ingroup comparisons $(64 \%)$, but reached a percentage that indicated saturation for outgroup comparisons $(43 \%)$.

This difference between the more closely and distantly related clade was also observed in the plots shown in Fig. 2 of transitions and transversions against divergence distances ( $p$-distances). In these plots, the numbers of transitions and transversions that have occurred over the evolutionary distance between all possible pairs of yeast species in the data set are mapped against $p$-distances. The approximately equal number of third position changes for ingroup and outgroup comparisons indicated saturation only for this class of changes. After determining which species comparisons accounted for the most divergent data points in this transition plot, it was found that the ingroup comparisons showed a distribution concordant with presumed evolutionary distances among the species (distant species showed the largest number of changes). Therefore, it was concluded that third position transitions were not saturated at the more recent evolutionary divergences (ingroup comparisons). However, they are not useful for the evaluation of more distant relationships (outgroup comparisons).

As it was shown that the three codon positions contain very different levels of useful phylogenetic information, separate phylogenetic analyses of each position were performed to test the congruence of the resulting trees with each other and with trees derived from amino acid sequences. The analyses of first and second positions gave generally compatible results. The analysis of third position data resulted in an obvious misplacement of an outgroup species, Schizosaccharomyces pombe. As an Archaeascomycete, this species is expected to be more distantly related to the ingroup than is the ascomycetous Neurospora crassa. However, third position analysis resolved closer relationships, as was expected, after these data confirmed empirically their relevance and importance (Kälersjö et al., 1999). The highly variable third position characters were shown to be influenced by compositional biases, such as the overall $\mathrm{G}+\mathrm{C}$ content. The $\mathrm{G}+\mathrm{C}$ content, which is not specific to single groups of fungi, tends to bring a degree of spurious similarity into comparisons among widely separated fungi that share this bias. The observed compositional bias $(\mathrm{G}+\mathrm{C}$ content) confers structure on the data, especially potential homoplastic data. Therefore, they become misleading the more the $\mathrm{G}+\mathrm{C}$ content departs from the mean range. In contrast, unstructured homoplasy, which can be understood as 'noise', hardly affects the probability of retrieving the best possible phylogeny (Wenzel \& Siddall, 1999). In comparisons of very distantly related taxa, however, as had to be done in our study to include appropriate outgroups, frequently changing sites approached probable structured randomness and were not analytically useable without down-weighting the most frequent changes.

The codon-position weighting scheme and the exclusion of third positions or third position transitions were required so that codon positions other than the second position could be used to analyse the outgroup and ingroup species together. In addition, the same salvage of useful information could be accomplished by application of combined codon-position weight and change-frequency weights to the complete data set. The latter procedure results in only one tree, as opposed to the 203 and 16 trees offered by the alternative techniques. The results obtained by the weighted analyses were highly similar to those obtained with inferred amino acid sequences. Minor differences were observed in the branching order within the groups detected. Cautious weighting proved to be effective in optimizing the useable information that could be extracted from a data set that combined unequal rates of evolution, as is typically found in sequence analyses of genes that encode proteins subject to strong selection.

The actin gene tree showed that pathogenic Candida species were concentrated in, but not confined to, group A. The recent divergence of Candida albicans and Candida dubliniensis (Sullivan et al., 1995) was confirmed. A more distant relationship between Candida albicans and Candida parapsilosis, as reflected in actin sequences, is consistent with analyses of the large-subunit rRNA gene (Kurtzman \& Robnett, 1998). Our analyses did not resolve details of the relationships between Candida tropicalis, Candida maltosa and Candida viswanathii, which clustered closely together within group A.

The clustering of Clavispora and Metschnikowia species with Pichia/Candida guilliermondii, Debaryomyces etchellsii and Candida zeylanoides in group B is different from the findings of most rDNA analyses, which place Clavispora and Metschnikowia species in a single clade, distantly related to any others. Their distinct relationship to other Hemiascomycetes is supported by the presence of large deletions in their rDNA sequences. However, no deletions are found in the actin genes of selected Metschnikowia and Clavispora species, due to strong selective forces operating on these sequences that lead to the observed high degree of conservation. Only one early analysis of the small-subunit rRNA gene (Barns et al., 1991) places Candida lusitaniae next to our group A, with its closest neighbour being Candida guilliermondii. The other three species of group B are reportedly close to Candida albicans and related species (Ohkuma et al., 1993; Cai et al., 1996; Mannarelli \& Kurtzman, 1998). More comprehensive studies (Kurtzman \& Robnett, 1997, 1998; Kurtzman \& Blanz, 1998), showed several species that were not included in this study incor- 
porated in clusters that included Pichia/Candida guilliermondii, Debaryomyces etchellsii and Candida zeylanoides. The difference between our well-defined group $\mathrm{B}$ and the more complex grouping seen in rDNA analyses may result from different evolution of the rDNA cluster and the actin gene. The relatively close relationship between our group A and the cluster containing Clavispora and Metschnikowia was confirmed by the significant bootstrap support for the link between groups A and B.

Within Kluyveromyces, two or three clusters have been identified by phenotypic and genotypic analyses (reviewed by Lachance, 1993) and by sequence analysis of the small subunit rDNA gene (Cai et al., 1996). The closely related Kluyveromyces marxianus and Kluyveromyces lactis belong to one of these previously recognized clusters that is considered to be monophyletic and well demarcated, worthy of recognition as a distinct genus as proposed by Cai et al. (1996). This cluster was found to be a sister group to other coenzyme- $\mathrm{Q}_{6}\left(\mathrm{Co}-\mathrm{Q}_{6}\right)$ yeasts in our analysis, including two Saccharomyces species, Candida glabrata and Kluyveromyces polysporus. Our group C, which encompassed the Kluyveromyces species and their relatives, was the least robust of our four groups. It was split in the analysis of second codon positions and Kluyveromyces polysporus was separated from it in the analysis of the first and second codon positions, weighted according to codon position and change frequency. This was most likely due to the lack of informative characters in these positions, as group $\mathrm{C}$ was supported by significant bootstrap values in the weighted analysis of all three codon positions. The whole group $\mathrm{C}$ represents more than one genus, but all species within it are unified in the $\mathrm{Co}-\mathrm{Q}_{6}$ system (Cai et al., 1996).

Pichia is a very diverse genus that includes yeasts with Co-Q systems 7, 8 and 9. They are dispersed in six major clades throughout the ascomycetous yeasts, according to rDNA analyses (Kurtzman \& Robnett, 1998). The Pichia species that were found in species group D appeared to be homogeneous. They are known to be closely related to cactophilic Pichia species (Shen \& Lachance, 1993) and certain Issatchenkia species, e.g. Issatchenkia orientalis. Pichia jadinii constitutes a taxon separate from the others (Yamada et al., 1994, 1995; Kurtzman \& Robnett, 1998).

Saccharomycopsis capsularis is classified in the Saccharomycopsidaceae, a distinct family with abundant development of true mycelium in some species and coenzyme $\mathrm{Co}-\mathrm{Q}_{8}$. The species of this family are known to form a separate clade at the generic level based on the large rRNA subunit (Kurtzman \& Smith, 1998). Based on our analysis of the actin gene, Saccharomycopsis capsularis evolved separately from the other budding yeasts that we investigated.

Co-Q data and $\mathrm{G}+\mathrm{C}$ contents (reviewed by Kurtzman \& Fell, 1998; Molnár et al., 1996; Villa \& Storck, 1968) provide useful characteristics in yeast taxonomy and were compared with the species groups that we detected (Table 2). The major Co-Q system is generally homogeneous among species within a monophyletic genus (Yamada et al., 1976). Nuclear $\mathrm{G}+\mathrm{C}$ contents usually vary by no more than $10 \%$ within a monophyletic genus. Overlaps between unrelated taxa are known for both characters. Therefore, their homogeneity may or may not indicate monophyly, but their heterogeneity supports polyphyly at the genus level (Kurtzman, 1998). The $\mathrm{G}+\mathrm{C}$ contents of the partial actin gene sequences were slightly higher than the nuclear $\mathrm{G}+\mathrm{C}$ contents, when the latter was detected by buoyant density in caesium salt gradients. However, there were some species for which the nuclear $\mathrm{G}+\mathrm{C}$ contents, determined by thermal denaturation, were higher than the genic $\mathrm{G}+\mathrm{C}$ contents (e.g. Candida viswanathii and Candida zeylanoides). Group A $\left(\mathrm{Co}-\mathrm{Q}_{9}\right)$ appeared to be homogeneous in its Co-Q system, although this was not determined for two species. However, the range of the nuclear $\mathrm{G}+\mathrm{C}$ content in this group increased significantly from $7 \cdot 6 \%$ in the monophyletic lineage excluding Candida viswanathii to $13.1 \%$ in the same lineage including Candida viswanathii. The genera Metschnikowia and Clavispora, combined in group B, are known to be only weakly associated (no significant bootstrap support in rDNA analyses, different Co-Q systems) (Kurtzman \& Robnett, 1998). Therefore, the apparent close relationship between them could be an artefact of underestimation of their evolutionary divergence. Again, the range of the nuclear $\mathrm{G}+\mathrm{C}$ contents increased from $7 \cdot 2 \%$ in the main group to $19 \cdot 1 \%$ after inclusion of Candida zeylanoides. Groups $\mathrm{C}\left(\mathrm{Co}-\mathrm{Q}_{6}\right)$ and $\mathrm{D}(\mathrm{Co}-$ $\mathrm{Q}_{7}$ ) were homogeneous in their Co-Q systems and in their ranges of nuclear $\mathrm{G}+\mathrm{C}$ content $(8.8$ and $6.2 \%$, respectively). These data support the monophyly of each of these groups. The actin tree showed coherence with the Co-Q systems and $\mathrm{G}+\mathrm{C}$ levels within each of the groups.

We conclude that the actin tree is compatible with the phylogenies generated from rDNA sequences, other than in the positioning of the Metschnikowial Clavispora clade. The identification of four potentially monophyletic groups within the diversity of the taxa investigated is a noteworthy advance in yeast systematics, as even the currently recognized teleomorph genera of ascomycetous yeasts are not monophyletic. The actin gene proved to be a valuable phylogenetic marker, sufficiently conserved to allow an unambiguous alignment and variable enough to resolve basal lineages significantly for the entire ingroup. It could be useful for the assignment of ascomycetous species to groups that should subsequently be resolved further using sequences of higher variability. Some species relationships within the detected groups could not be supported by significant bootstrap values. However, all anamorph/teleomorph pairs included were validated by high bootstrap values. The investigation of more species using actin gene sequences may reduce 
the heterogeneity in such highly polyphyletic genera as Pichia and Kluyveromyces and may facilitate the search for as-yet unknown anamorph/teleomorph connections. The investigation of more genes (e.g. elongation factors or tubulin) is required for the further development of a natural classification of the Hemiascomycetes.

\section{ACKNOWLEDGEMENTS}

We are grateful to David Yarrow for providing type strains and advice on yeast taxonomy, Richard Summerbell and an anonymous referee for productive comments on the manuscript, Cletus Kurtzman for discussion of our results and Ok Cha Lee for technical support on the biochemical identification of yeast cultures. The work was supported by a project grant from the National Health \& Medical Research Council, Australia (\#960792), to W.M., a grant from the German Research Society (Me 1393/1-1) to W.M., two Grants-in-Aid from the Westmead Research Foundation, Australia, to W.M., an initiation grant from the Westmead Research Foundation to H.M.D. and a PhD scholarship from the Centre for Infectious Diseases and Microbiology, Australia, to H.M.D.

\section{REFERENCES}

Barns, S. M., Lane, D. J., Sogin, M. L., Bibeau, C. \& Weisburg, W. G. (1991). Evolutionary relationships among pathogenic Candida species and relatives. J Bacteriol 173, 2250-2255.

Berbee, M. L. \& Taylor, J. W. (1992). Detecting morphological convergence in true fungi, using $18 \mathrm{~S}$ rRNA gene sequence data. Biosystems 28, 117-125.

Bhattacharya, D. \& Ehlting, J. (1995). Actin coding regions: gene family evolution and use as a phylogenetic marker. Arch Protistenkd 145, 155-164.

Bhattacharya, D., Stickel, S. K. \& Sogin, M. L. (1991). Molecular phylogenetic analysis of actin genic regions from Achlya bisexualis (Oomycota) and Costaria costata (Chromophyta). $J$ Mol Evol 33, 525-536.

Bouget, F.-Y., Kerbourc'h, C., Liaud, M.-F., Loiseaux de Goer, S., Quatrano, R. S., Cerff, R. \& Kloareg, B. (1995). Structural features and phylogeny of the actin gene of Chondrus crispus (Gigartinales, Rhodophyta). Curr Genet 28, 164-172.

Brown, W. M., Prager, E. M., Wang, A. \& Wilson, A. C. (1982). Mitochondrial DNA sequences of primates: tempo and mode of evolution. J Mol Evol 18, 225-239.

Cai, J., Roberts, I. N. \& Collins, M. D. (1996). Phylogenetic relationships among members of the ascomycetous yeast genera Brettanomyces, Debaryomyces, Dekkera, and Kluyveromyces deduced by small-subunit rRNA gene sequences. Int $J$ Syst Bacteriol 46, 542-549.

Cox, G. M., Rude, T. H., Dykstra, C. C. \& Perfect, J. R. (1995). The actin gene from Cryptococcus neoformans: structure and phylogenetic analysis. J Med Vet Mycol 33, 261-266.

Deshler, J. O., Larson, G. P. \& Rossi, J. J. (1989). Kluyveromyces lactis maintains Saccharomyces cerevisiae intron-encoded splicing signals. Mol Cell Biol 9, 2208-2213.

Drouin, G., Moniz de Sa, M. \& Zuker, M. (1995). The Giardia lamblia actin gene and the phylogeny of eukaryotes. $J$ Mol Evol 41, 841-849.

Ducroz, J.-F., Volobouev, V. \& Granjon, L. (1998). A molecular perspective on the systematics and evolution of the genus Arvicanthis (Rodentia, Muridae): inferences from complete cytochrome b gene sequences. Mol Phylogenet Evol 10, 104-117.

Farris, J. S. (1966). Estimation of conservatism of characters by constancy within biological populations. Evolution 20, 587-591.

Farris, J. S. (1989). The retention index and the rescaled consistency index. Cladistics 5, 417-419.

Felsenstein, J. (1985). Confidence limits on phylogenies: an approach using the bootstrap. Evolution 39, 783-791.

Fitch, W. M. (1996). Uses for evolutionary trees. In New Uses for New Phylogenies, pp. 116-133. Edited by P. H. Harvey, A. J. L. Brown, J. M. Smith \& S. Nee. Oxford: Oxford University Press.

Fuson, G. B., Price, C. W. \& Phaff, H. J. (1980). Deoxyribonucleic acid base sequence relatedness among strains of Pichia ohmeri that produce dimorphic ascospores. Int J Syst Bacteriol 30, 217-219.

Gallwitz, D. \& Sures, I. (1980). Structure of a split yeast gene: complete nucleotide sequence of the actin gene in Saccharomyces cerevisiae. Proc Natl Acad Sci US A 77, 2546-2550.

Gilbert, D. (1996). SeqPup version 0.6d. Bloomington, IN: Indiana University.

Goloboff, P. A. (1991). Homoplasy and the choice among cladograms. Cladistics 7, 215-232.

Hendriks, L., Goris, A., van de Peer, Y., Neefs, J. M., Vancanneyt, M., Kersters, K., Berny, J. F., Hennebert, G. L. \& de Wachter, R. (1992). Phylogenetic relationships among ascomycetes and ascomycete-like yeasts as deduced from small ribosomal subunit RNA sequences. Syst Appl Microbiol 15, 98-104.

Hillis, D. H. \& Bull, J. J. (1993). An empirical test of bootstrapping as a method for assessing confidence in phylogenetic analysis. Syst Biol 42, 182-192.

Hillis, D. M. \& Huelsenbeck, J. P. (1992). Signal, noise, and reliability in molecular phylogenetic analyses. J Hered $\mathbf{8 3}$, 189-195.

Huang, M.-E., Souciet, J.-L., Chuat, J.-C. \& Galibert, F. (1996). Identification of act4, a novel essential actin-related gene in the yeast Saccharomyces cerevisiae. Yeast 12, 839-848.

Johnson, K. P. \& Sorenson, M. D. (1998). Comparing molecular evolution in two mitochondrial protein coding genes (cytochrome $\mathrm{b}$ and ND2) in the dabbling ducks (Tribe: Anatini). Mol Phylogenet Evol 10, 82-94.

Kälersjö, M., Albert, V. A. \& Farris, J. S. (1999). Homoplasy increases phylogenetic structure. Cladistics 15, 91-93.

Kan, V. L. (1993). Polymerase chain reaction for the diagnosis of candidemia. J Infect Dis 168, 779-783.

Kluge, A. G. \& Farris, J. S. (1969). Quantitative phyletics and the evolution of anurans. Syst Zool 18, 1-32.

Knight, A. \& Mindell, D. P. (1993). Substitution bias, weighting of DNA sequence evolution, and the phylogenetic position of fea's viper. Syst Biol 42, 18-31.

Kumar, S., Tamura, K. \& Nei, M. (1993). MEGA: Molecular Evolutionary Genetics Analysis 1.01. Pennsylvania, PA: Pennsylvania State University.

Kurtzman, C. P. (1984). Synonymy of the yeast genera Hansenula and Pichia demonstrated through comparisons of deoxyribonucleic acid relatedness. Antonie Leeuwenhoek 50, 209-217. Kurtzman, C. P. (1998). Nuclear DNA hybridization: quantitation of close genetic relationships. In The Yeasts, a Taxonomic Study, 4th edn, pp. 63-68. Edited by C. P. Kurtzman \& J. W. Fell. Amsterdam: Elsevier. 
Kurtzman, C. P. \& Blanz, P. A. (1998). Ribosomal RNA/DNA sequence comparisons for assessing phylogenetic relationships. In The Yeasts, a Taxonomic Study, 4th edn, pp. 69-74. Edited by C. P. Kurtzman \& J. W. Fell. Amsterdam: Elsevier.

Kurtzman, C. P. \& Fell, J. W. (editors) (1998). The Yeasts, a Taxonomic Study, 4th edn. Amsterdam: Elsevier

Kurtzman, C. P. \& Robnett, C. J. (1994). Synonymy of the yeast genera Wingea and Debaryomyces. Antonie Leeuwenhoek 66, 337-342.

Kurtzman, C. P. \& Robnett, C. J. (1997). Identification of clinically important ascomycetous yeasts based on nucleotide divergence in the $5^{\prime}$ end of the large-subunit (26S) ribosomal DNA gene. $J$ Clin Microbiol 35, 1216-1223.

Kurtzman, C. P. \& Robnett, C. J. (1998). Identification and phylogeny of ascomycetous yeasts from analysis of nuclear large subunit (26S) ribosomal DNA partial sequences. Antonie Leeuwenhoek 73, 331-371.

Kurtzman, C. P. \& Smith, M. T. (1998). Saccharomycopsis Schiönning. In The Yeasts, a Taxonomic Study, 4th edn, pp. 374-386. Edited by C. P. Kurtzman \& J. W. Fell. Amsterdam: Elsevier.

Lachance, M.-A. (1993). Kluyveromyces: systematics since 1970. Antonie Leeuwenhoek 63, 95-104.

Liu, Y. J., Whelen, S. \& Hall, B. D. (1999). Phylogenetic relationships among ascomycetes: evidence from an RNA polymerase II subunit. Mol Biol Evol 16, 1799-1808.

Lloyd, A. T. \& Sharp, P. M. (1992). Evolution of codon usage patterns: the extent and nature of divergence between Candida albicans and Saccharomyces cerevisiae. Nucleic Acids Res 20, 5289-5295.

Losberger, C. \& Ernst, J. F. (1989). Sequence of the Candida albicans gene encoding actin. Nucleic Acids Res 17, 9488.

Lott, T. J., Kuykendall, R. J. \& Reiss, E. (1993). Nucleotide sequence analysis of the 5.8S rDNA and adjacent ITS2 region of Candida albicans and related species. Yeast 9, 1199-1206.

Maddison, W. P. \& Maddison, D. R. (1997). MACCLADE . Analysis of Phylogeny and Character Evolution, version 3.07. Sunderland, MA: Sinauer Associates.

Mannarelli, B. M. \& Kurtzman, C. P. (1998). Rapid identification of Candida albicans and other human pathogenic yeasts by using short oligonucleotides in a PCR. J Clin Microbiol 36, $1634-1641$.

Mendonça-Hagler, L. C., Hagler, A. N. \& Kurtzman, C. P. (1993). Phylogeny of Metschnikowia species estimated from partial rRNA sequences. Int J Syst Bacteriol 43, 368-373.

Mertins, P. \& Gallwitz, D. (1987). A single intronless actin gene in the fission yeast Schizosaccharomyces pombe: nucleotide sequence and transcripts formed in homologous and heterologous yeast. Nucleic Acids Res 15, 7369-7379.

Meyer, W., Latouche, G. N., Daniel, H.-M., Thanos, M., Mitchell, T. G., Yarrow, D., Schönian, G. \& Sorrell, T. C. (1997). Identification of pathogenic yeasts of the imperfect genus Candida by polymerase chain reaction fingerprinting. Electrophoresis 18, $1548-1559$.

Meyer, S. A., Payne, R. W. \& Yarrow, D. (1998). Candida Berkout. In The Yeasts, a Taxonomic Study, 4th edn, pp. 454-573. Edited by C. P. Kurtzman \& J. W. Fell. Amsterdam: Elsevier.

Molnár, O., Prillinger, H., Lopandic, K., Weigang, F. \& Staudacher, E. (1996). Analysis of coenzyme Q systems, monosaccharide patterns of purified cell walls, and RAPD-PCR patterns in the genus Kluyveromyces. Antonie Leeuwenhoek 70, 67-78.

Montrocher, R., Verner, M.-C., Briolay, J., Gautier, C. \& Marmeisse, R. (1998). Phylogenetic analysis of the Saccharomyces cerevisiae group based on polymorphisms of rDNA spacer sequences. Int J Syst Bacteriol 48, 295-303.

$\mathbf{N g}, \mathbf{R}$. \& Abelson, J. (1980). Isolation and sequence of the gene for actin in Saccharomyces cerevisiae. Proc Natl Acad Sci US A 77, 3912-3916.

Ohkuma, M., Hwang, C. W., Masuda, Y., Nishida, H., Sugiyama, J., Ohta, A. \& Takagi, M. (1993). Evolutionary position of $n$ alkane-assimilating yeast Candida maltosa shown by nucleotide sequence of small-subunit ribosomal RNA gene. Biosci Biotechnol Biochem 57, 1793-1794.

Price, C. W., Fuson, G. B. \& Phaff, H. J. (1978). Genome comparison in yeast systematics: delimitation of species within the genera Schwanniomyces, Saccharomyces, Debaryomyces, and Pichia. Microbiol Rev 42, 161-193.

Shen, R. \& Lachance, M.-A. (1993). Phylogenetic study of ribosomal DNA of cactophilic Pichia species by restriction mapping. Yeast 9, 315-330.

Sheterline, P. \& Sparrow, J. C. (1994). Actin. Protein Profile 1, $1-121$

Starmer, W. T., Phaff, H. J., Miranda, M. \& Miller, M. W. (1978). Pichia amethionina, a new heterothallic yeast associated with the decaying stems of cereoid cacti. Int J Syst Bacteriol 28, 433-441.

Sullivan, D. J., Westerneng, T. J., Haynes, K. A., Bennett, D. E. \& Coleman, D. C. (1995). Candida dubliniensis sp. nov.: phenotypic and molecular characterization of a novel species associated with oral candidosis in HIV-infected individuals. Microbiology 141, 1507-1521.

Swofford, D. L. (1993). PAUP, Phylogenetic Analysis Using Parsimony, version 3.1.1Champaign, IL: Illinois Natural History Survey.

Villa, V. D. \& Storck, R. (1968). Nucleotide composition of nuclear and mitochondrial deoxyribonucleic acid of fungi. $J$ Bacteriol 96, 184-190.

Wenzel, J. W. \& Siddall, M. E. (1999). Noise. Cladistics 15, 51-64.

Wery, J., Dalderup, M. J. M., ter Linde, J., Boekhout, T. \& van Ooyen, A. J. J. (1996). Structural and phylogenetic analysis of the actin gene from the yeast Phaffia rhodozyma. Yeast 12, 641-651.

Yamada, Y., Nojiri, M., Matsuyama, M. \& Kondo, K. (1976). Coenzyme Q system in the classification of the ascosporogenous yeast genera Debaryomyces, Saccharomyces, Kluyveromyces, and Endomycopsis. J Gen Appl Microbiol 22, 325-337.

Yamada, Y., Maeda, K. \& Mikata, K. (1994). The phylogenetic relationships of the hat-shaped ascospore-forming, nitrateassimilating Pichia species, formerly classified in the genus Hansenula Sydow et Sydow, based on the partial sequences of $18 \mathrm{~S}$ and $26 \mathrm{~S}$ ribosomal RNAs (Saccharomycetaceae): the proposals of three new genera, Ogataea, Kuraishia, and Nakazawaea. Biosci Biotechnol Biochem 58, 1245-1257.

Yamada, Y., Matsuda, M. \& Mikata, K. (1995). The phylogenetic relationships of Pichia jadinii, formerly classified in the genus Hansenula, and related species based on the partial sequences of $18 \mathrm{~S}$ and 26S ribosomal RNAs (Saccharomycetaceae). Biosci Biotechnol Biochem 59, 518-520. 